\title{
A Three-Component Carboxylic acid-Bipyridine Lattice Inclusion Host. Supramolecular Synthesis of Ternary Cocrystals
}

Balakrishna R. Bhogala, Srinivas Basavoju, and Ashwini Nangia*

School of Chemistry, University of Hyderabad, Hyderabad 500046, India. E-mail:ashwini_nangia@rediffmail.com

\section{Supporting Information}

\section{Experimental Section}

1,3cis,5cis-Cyclohexanetricarboxylic acid $\left(\mathrm{H}_{3} \mathrm{CTA}\right.$, m.p. $\left.216-217^{\circ} \mathrm{C}\right)$ was purchased from Aldrich and 4,4'-bipyridine (bipy, m.p. $110-114^{\circ} \mathrm{C}$ ) from Lancaster. 1,2-bis(4pyridyl)ethane ${ }^{1}$ (bipy-eta, m.p. $110-112{ }^{\circ} \mathrm{C}$ ), 1,4-bis(4-pyridyl)butane ${ }^{2}$ (bipy-bu, m.p. $116-118{ }^{\circ} \mathrm{C}$ ) and trans-bis(4-pyridyl)ethylene dioxide ${ }^{1 \mathrm{a}, 3}$ (bipy-ete-NO, m.p. $275-280{ }^{\circ} \mathrm{C}$ ) were synthesized as described.

\section{Co-crystallization}

$\mathbf{H}_{3}$ CTA -bipy•bipy-eta (1:1:0.5) 1. A mixture of 1,3 cis,5cis-cyclohexanetricarboxylic acid, 4,4'-bipyridine and 1,2-bis(4-pyridyl) ethane in 2:2:1 ratio in EtOH/benzene was heated to dissolve the components and allowed to crystallize at room temperature. Crystals of $\mathrm{H}_{3} \mathrm{CTA} \bullet$ bipy•bipy-eta $(2: 2: 1)$ were obtained in a week, m.p. $175-180{ }^{\circ} \mathrm{C}$. The composition of the molecular complex was indicated by ${ }^{1} \mathrm{H}-\mathrm{NMR}$ (Fig. S1). Single crystal X-ray diffraction confirms the structure of 1 .

\section{$\mathrm{H}_{3} \mathrm{CTA} \cdot$ bipy-eta・(bipy-bu $)_{0.5} 2$}

2•(p-xylene $)_{0.5}$. A mixture of $\mathrm{H}_{3} \mathrm{CTA}$, bipy-eta and bipy-bu in 2:2:1 ratio in $n$-propanol $/ p$ xylene gave crystals (m.p. $139^{\circ} \mathrm{C}, \mathrm{T}_{\text {onset }}$, DSC) at room temperature in a week. Single crystal X-ray shows that the asymmetric unit contains one molecule each of $\mathrm{H}_{3} \mathrm{CTA}$ and bipy-eta and 0.5 molecule each of bipy-bu and $p$-xylene.

2•(p-dichlorobenzene $)_{0.5}$. A mixture of $\mathrm{H}_{3} \mathrm{CTA}$, bipy-eta, bipy-bu and $p$-dichlorobenzene in $2: 2: 1: 1.5$ ratio in ethanol gave crystals $\left(\mathrm{mp} 159-162^{\circ} \mathrm{C}\right)$ at room temperature in a week. Single crystal X-ray shows that the asymmetric unit contains one molecule each of $\mathrm{H}_{3} \mathrm{CTA}$ and bipy-eta and 0.5 molecule each of bipy-bu and $p$-dichlorobenzene.

$\mathbf{H}_{3} \mathbf{C T A} \cdot(\text { bipy })_{0.5} \bullet^{\bullet}(\text { bipy-ete-N-oxide })_{0.5}$ 3. A mixture of $\mathrm{H}_{3} \mathrm{CTA}$ (21.6 $\mathrm{mg}, 0.1 \mathrm{mmol}$ ), bipy $(15.6 \mathrm{mg}, 0.1 \mathrm{mmol})$ and bipy-ete-N-oxide $(10.7 \mathrm{mg}, 0.05 \mathrm{mmol})$ was heated to dissolve in ethanol. Block shaped crystals (m.p. $258{ }^{\circ} \mathrm{C}$ ) were obtained on slow evaporation. Single crystal X-ray diffraction shows the presence of $\mathrm{H}_{3} \mathrm{CTA}$, bipy and bipy-ete-N-oxide in 1:0.5:0.5 ratio.

\section{X-Ray crystallography}

Single crystal X-ray data for $\mathbf{1}$ and $\mathbf{3}$ was collected on a Enraf-Nonius MACH3 diffractometer and $\mathbf{2 \bullet}(\boldsymbol{p} \text {-xylene })_{0.5}$ and $\mathbf{2 \bullet}(\boldsymbol{p} \text {-dichlorobenzene })_{0.5}$ were collected on a 
Bruker-CCD SMART 1000 diffractometer (Mo-K $\alpha$ radiation, $\lambda=0.71073 \AA$ ). Structures were solved by the direct methods and refined on $F^{2}$ with SHELX-97 ${ }^{4}$ and SHELXTL. ${ }^{5}$ In compounds $1,2 \cdot(p \text {-xylene })_{0.5}$ and $2 \cdot(p \text {-dichlorobenzene })_{0.5}$ acidic $\mathrm{H}$ atoms only and in compound $\mathbf{3}$ all $\mathrm{H}$ atoms were located from difference Fourier maps, $\mathrm{H}$ atoms bonded to carbon were fixed in calculated positions.

$1 \mathrm{C}_{25} \mathrm{H}_{26} \mathrm{~N}_{3} \mathrm{O}_{6}, M=464.49$, Enraf-Nonius MACH3, 298(2) $\mathrm{K}$, monoclinic, $a=33.167(7)$, $b=9.954(2), c=14.988(3) \AA, \beta=110.91(3)^{\circ}, V=4622.3(19) \AA^{3}$, space group $C 2 / c, Z=$ $8, \mu(\mathrm{Mo}-\mathrm{K} \alpha)=0.097 \mathrm{~mm}^{-1}$, size $0.40 \times 0.45 \times 0.52 \mathrm{~mm} .5383$ total reflections of which 5302 were independent, 3011 observed $[I>2 \sigma(I)]$. Refinement against $F^{2}$ with 319 parameters, $R_{1}[I>2 \sigma(I)]=0.0530$.

2.(p-xylene $)_{0.5} \mathrm{C}_{32} \mathrm{H}_{37} \mathrm{~N}_{3} \mathrm{O}_{6}, M=559.65$, Bruker Nonius Smart Apex CCD, 100(2) $\mathrm{K}$, triclinic, $a=5.7110(4), b=14.1003(10), c=18.3960(13) \AA, \alpha=86.100(1), \beta=$ 84.560(1), $\gamma=82.123(1)^{\circ}, V=1458.51(18) \AA^{3}$, space group $P \overline{1}, Z=2, \mu$ (Mo-K $\left.\alpha\right)=$ $0.088 \mathrm{~mm}^{-1}$, size $0.13 \times 0.39 \times 0.50 \mathrm{~mm}$. 17524 total reflections of which 5730 were independent, 5007 observed $[I>2 \sigma(I)]$. Refinement against $F^{2}$ with 383 parameters, $R_{1}[I$ $>2 \sigma(I)]=0.0641$.

2.(p-dichlorobenzene) $)_{0.5} \mathrm{C}_{31} \mathrm{H}_{34} \mathrm{ClN}_{3} \mathrm{O}_{6}, M=580.06$, Bruker Nonius Smart Apex CCD, 100(2) K, triclinic, $a=5.6882(7), b=14.0309(18), c=18.390(2) \AA, \alpha=85.767(2) \beta=$ $84.034(2), \gamma=81.877(2)^{\circ}, V=1442.5$ (3) $\AA^{3}$, space group $P \overline{1}, Z=1, \mu(\mathrm{Mo}-\mathrm{K} \alpha)=0.182$ $\mathrm{mm}^{-1}$, size $0.12 \times 0.26 \times 0.29 \mathrm{~mm}$. 14907 total reflections of which 5470 were independent, 4327 observed $[I>2 \sigma(I)]$. Refinement against $F^{2}$ with 383 parameters, $R_{1}[I$ $>2 \sigma(I)]=0.0479$.

$3 \mathrm{C}_{20} \mathrm{H}_{21} \mathrm{~N}_{2} \mathrm{O}_{7}, M=401.39$, Enraf-Nonius MACH3, 298(2) $\mathrm{K}$, monoclinic, $a=$ 6.1002(12), $b=12.531(3), c=25.138(5) \AA, \beta=93.73(3)^{\circ}, V=1917.6(7) \AA^{3}$, space group $P 2_{1} / n, Z=4, \mu(\mathrm{Mo}-\mathrm{K} \alpha)=0.106 \mathrm{~mm}^{-1}$, size $0.30 \times 0.28 \times 0.20 \mathrm{~mm} .4790$ total reflections of which 4384 were independent, 2559 observed $[I>2 \sigma(I)]$. Refinement against $F^{2}$ with 346 parameters, $R_{1}[I>2 \sigma(I)]=0.0618$.

\section{References}

(1) (a) Whitten, D. G.; McCall, M. T. J. Am. Chem. Soc. 1969, 91, 5097. (b) Yamin, M.; Fuoss, R. M. J. Am. Chem. Soc. 1953, 75, 4860.

(2) Richards, D. H.; Scilly, N. F.; Williams, F. J. Chem. Ind. 1970, 40, 1298.

(3) Jana N. K.; Verkade, J. D. Org. Lett. 2003, 5, 3787.

(4) (a) SHELXS-97: Sheldrick, G. M. Program for the Solution of Crystal Structures, University of Göttingen, Germany, 1997. (b) SHELXL-97: Sheldrick, G. M. Program for Crystal Structure Refinement, University of Göttingen, Germany, 1997.

(5) SHELXTL (version 6.14): Bruker AXS, Program for the Solution and Refinement of Crystal Structures, Wisconsin, USA, 2000. 


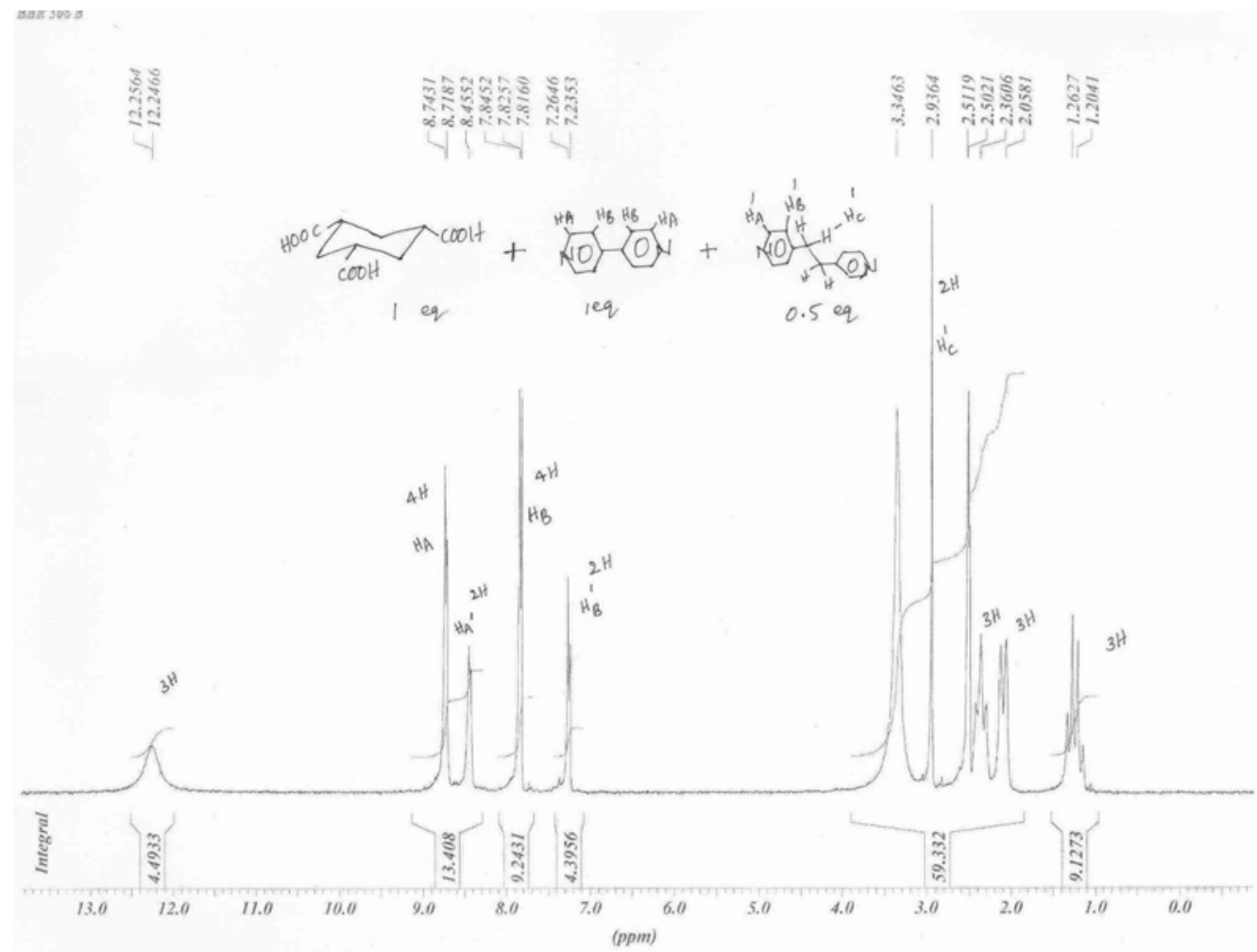

Figure S1 ${ }^{1} \mathrm{H}$ NMR shows the presence of $\mathrm{H}_{3} \mathrm{CTA}$, bipy and bipy-eta in a ratio of 2:2:1 in cocrystal $\mathbf{1}$. The X-ray structure confirms this stoichiometry. 


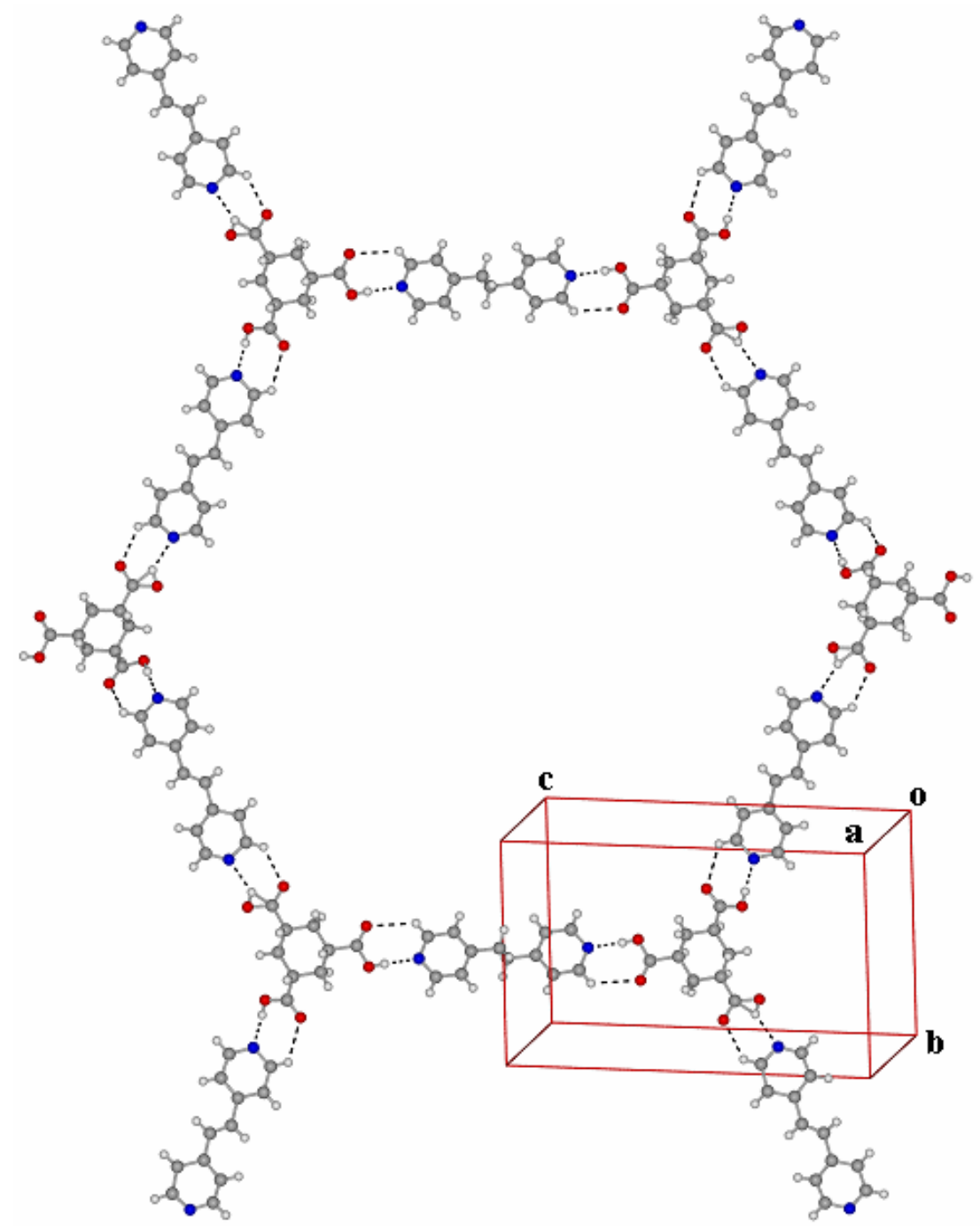

Figure S2 Crystal structure of $\mathrm{H}_{3} \mathrm{CTA} \cdot$ bipy-ete (bipy-eta) $)_{0.5}$ to show bipy-ete moieties along the $2_{1}$ screw axis and bipy-eta connectors along the $c$-direction. Note that different bipy bases occupy the "helix" and "connector" domains of the ternary structure. 